\title{
Gert Jan Gelderblom Editor-in-Chief, AAATE President-Elect
}

It is with deep sentiments that we have to share the information that our President-Elect, journal editor, board member, long lasting supporter and friend, Gert Jan Gelderblom suddenly passed away on the 30th December 2014.

We would like to express our condolence with Gert Jan's family and we wish them strength in the following days. In our minds we are with them in having to realise this incredible loss.

Our warmest feelings are also with all colleagues of Gert Jan and the team at Zuyd University, with whom we feel such a strong empathy.

Our field loses one of its founders and pioneers, a brilliant forward thinking and pushing expert and our Association an inspiring board member and future president.

We all lose a dear friend and we will miss you tremendously.

The Board of AAATE Past Presidents of AAATE

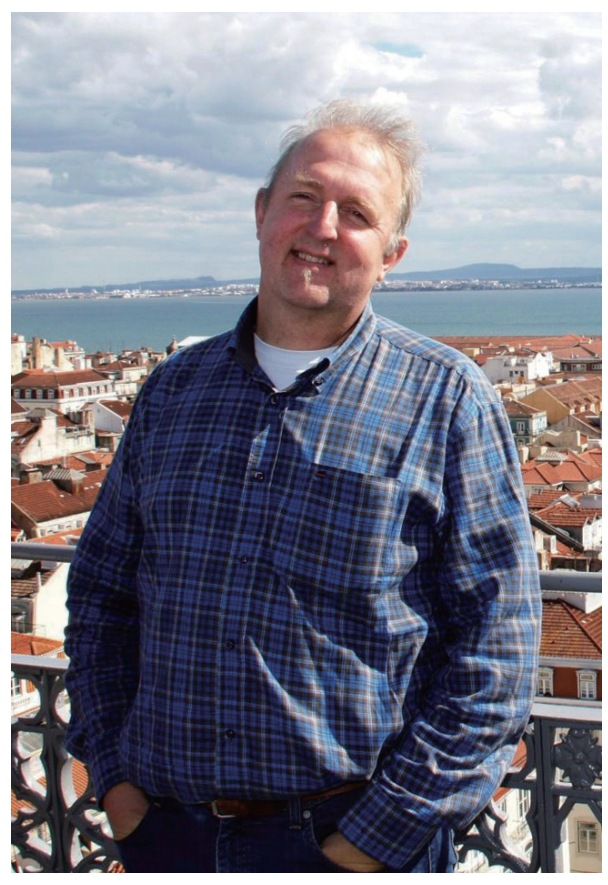

IOS Press b.v 